\title{
Transfers, Taxes and the NAIRU
}

\author{
DANIEL S. HAMERMESH
}

Just as war is too important to be left to the generals, the impact of taxes and transfers on the aggregate unemployment rate is too important to be left to the macroeconomists. I therefore subject the issue of how tax and transfer policy affects unemployment and aggregate supply to a detailed, microeconomic examination of the effects of individual tax and transfer program structures. This inductive approach is, I believe, likely to provide a far better guide to discovering how changes in these policies have worked through the economy than would a macroeconomic approach that ignored the programs' complexities.

Throughout the discussion we need to distinguish the programs' effects on two different aspects of economic performance. First, they may affect the measured nonaccelerating-inflation rate of unemployment (NAIRU). Such effects would be important for planning macroeconomic policy, though it is not clear how informative knowledge of any effects on the NAIRU is for learning about aggregate supply. Second, each tax and transfer policy may change the amount of employment observed at the NAIRU; assuming productive efficiency, this means that these policies will affect the amount of output, and thus per-capita incomes observed in the economy. It is this second set of effects that is more in the spirit of the supply-side discussions of recent years. Unlike the first effect, it is more than just an issue of measurement.

Before proceeding to present first a macro approach to the issue, then a detailed micro approach, it is worth considering some wellknown (to labor economists) aspects of labor force change over the past twenty years. For selected years of roughly comparable aggregate demand pressures (though 1969 was probably somewhat tighter than the other two years), we present the aggregate unemployment and participation rates, and unemployment rates,

Daniel S. Hamermesh is Professor of Economies, Michigan State University, and Research Associate, National Bureau of Economic Research, Cambridge, Mass. Helpful comments on an earlier verston of this paper were provided by Alan Blinder. 
participation rates and labor force shares of five demographic groups. Several features, in decreasing order of my estimate of their importance in the history of the U.S. labor market over the past 20 years, stand out: 1) The adult female participation rate has skyrocketed, causing that group's representation in the civilian labor force to jump from 30 to 38 percent; 2) As a result of the post-war baby boom, the teen-age share of the labor force has also increased, a rise that has been accentuated by the simultaneous rise in (mostly part-time) labor-market participation in this group; 3) The participation rates of older males have decreased drastically, substantially lowering their representation in the labor force. (This change is a major focus of my discussion in the fourth section below.); and 4) Partly as a result of the first two changes and their interaction (see Grant and Hamermesh, 1981), the unemployment. rate of teenagers has increased sharply. Teenagers are indeed one of only two groups among the five whose pattern of unemployment rates across the three years departs obviously from the aggregate rate. (The other is older men, whose unemployment rate is lower in 1979 than in 1957.)

\section{A Macro Approach TO THE EFFECTS OF TRANSFERS AND TAXES}

If you are an unreformed macroeconomist, and you believe that taxes and transfers have affected the NAIRU, your initial inclination should be to specify a time-series equation to estimate the direction and magnitude of their effects. In the case of unemployment insurance benefits, such a time-series model has been estimated by Grubel and Maki (1976). Postulating that the net effect will be positive, they find, in a regression of the logarithm of the aggregate unemployment rate on the gross replacement rate of UI benefits and other variables, that this effect is observed in the data. Unfortunately for believers in such models, the size of the effect is so large as to imply that unemployment would be reduced nearly to zero if the UI program were abolished.'

Taking this simplistic approach to its logical conclusion, we estimate in this section an equation explaining variations in aggregate unemployment. The dependent variable is $\log \left(\mathrm{U}^{*} / 100-\mathrm{U}^{*}\right)$, a transform of the adjusted unemployment rate. Rather than using the published aggregate unemployment rate, we use a constantweight average of unemployment rates of teenagers, women $20+$,

The implied effect of a .1 inerease in gross replacement by UI in the Grubel-Maki study is an extra 6.31 percentage points of unemployment? 
TABLE 1

Selected Labor Force Data, 1957, 1969, 1979

1957

1969

1979

Aggregate

Unemployment Rate

4.3

3.5

5.8

Participation Rate

59.6

60.1

63.7

Teens

Unemployment Rate

8.8

8.8

16.1

Participation Rate

49.7

49.4

58.1

Fraction of Labor Force

.064

.086

.092

Women $20+$

Unemployment Rate

4.1

3.7

5.7

Participation Rate

36.5

42.7

50.6

Fraction of Labor Force

.297

.340

.378

Men 20-24

Unemployment Rate

7.8

5.1

8.6

Participation Rate

87.0

82.8

86.6

Fraction of Labor Force

.054

.065

.080

Men 25-54

Unemployment Rate

Participation Rate

3.1

1.6

3.4

Fraction of Labor Force

97.1

96.1

94.4

.455

.395

.362

Men $55+$

Unemployment Rate

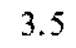

1.9

Participation Rate

63.4

56.1

46.7

Fraction of Labor Force

men 25-54, and other men, where the weights are their shares in the civilian labor force in 1957:I. This refinement circumvents the problem that growing replacement rates of transfer programs are observed to be positively correlated with an aggregate unemployment rate that is rising because of the very substantial changes in the demographic mix of the labor force that have occurred since 1957 . 
To represent transfer and tax policy, two variables are used, in each case with lags to avoid part of any problem that may be caused by simultaneity. These are: 1) NRR, the net replacement rate of transfer payments in aggregate. This is computed as personal transfer payments, divided by wages and salaries minus personal contributions for social insurance minus a prorated (by wages' share in personal income) share of personal income taxes; and 2) TAX, the sum of personal income taxes on wages and salaries, and individual and employer contributions for social insurance, all divided by the sum of wages and salaries and employer social insurance contributions. ${ }^{2}$ This is designed to measure any disincentive effects that taxes on wages and salaries may have beyond their effects through the financing of transfer payments.

Also included in the model are a time trend variable and the change in the rate of growth of per-capita real GNP. ${ }^{3}$ This acceleration term seems more appropriate than the growth rate itself, as it is hard to argue that the NAIRU will vary with the steady-state growth rate of an economy. The model is estimated over U.S. data from 1954:II through 1978:IV. Both simple lag terms in NRR and TAX are included, and variants that include polynomial distributed lags in these variables are also estimated. ${ }^{4}$ All of the equations are estimated using the Cochrane-Orcutt technique to account for first-order autocorrelation in the residuals.

The results of estimating four versions of the equation relating a logarithmic transformation of the adjusted unemployment rate to the variables defined above are presented in Table 2 . The change in the rate of per-capita real GNP growth has the expected negative sign. Interestingly, the trend coefficient is negative. (Remember, we have removed any trend effects produced by demographic changes in the labor force.) Including all lagged terms (in both NRR and TAX) significantly increases the explanatory power of the

\footnotetext{
${ }^{2}$ A TAX vartable that excluded employer contributions from both numerator and denoninator was also used in place of the variable discussed in the text. White the results were qualitatively similar, the coefficten of determination was in every case slightly lower.

"The model was also estimated with the theoretically improper variable, percent change in GNP. Though the $\mathrm{R}^{2}$ exceeded those reported for comparable equations in Table 2, and though the implications of NRR and TAX were the same as in the table, the lack of a good justification for this variable suggests the discussion should be based on the model including its rate of change.

"The polynomial lags wete estimated with the fat end-point coefficients constrained to equal zero. A test of the validity of these constraints in the equation in column $(4)$ yielded $F(3,87)=.49$. (The 95 percent significance level with these degrees of freedom is 2.71.)
} 
TABLE 2

Effects on $\log \left(\mathrm{U}^{*} / 100-\mathrm{U}^{*}\right)$

1954:11-1978:IV

(2)

(3)

(4)

Constant

$\begin{array}{cccc}-3.39 & -3.34 & -3.45 & -4.26 \\ (-17.93) & (-12.79) & (-19.01) & (-9.91)\end{array}$

GNP-GNP,

$-.036$

$-.037$

$-.047$

$-.045$

(sum of four

lagged terms)

$(-1.64)$

$(-1.66)$

$(-2.11)$

$(-2.04)$

Time

$-.011$

$-.011$

$-.014$

$-.022$

$(-3.01)$

$(-2.71)$

$(-3.04)$

$(-3.74)$

NRR - :

6.71

6.22

6.15

5.91

$(4.80)$

(4.79)

$(5.00)$

(4.87)

$\mathrm{NRR}_{-2}$

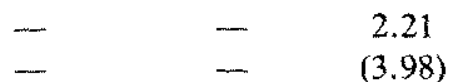

2.42

$(3,98)$

(4.44)

$\mathrm{NRR}_{-}{ }^{3}$

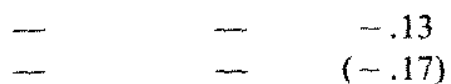

.27

$-$

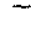

$(-.17)$

(.36)

$\mathrm{NRR}_{-4}$

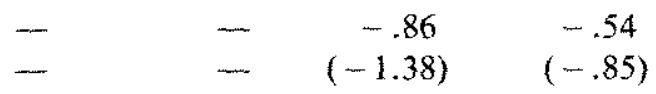

TAX

$-\quad-.361$

$-$

.15

(.13)

$\mathrm{TAX}_{\ldots 2}$
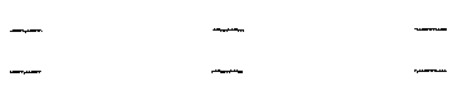

1.56

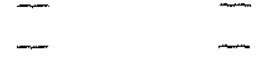

$(2.04)$

$\mathrm{TAX}_{-3}$

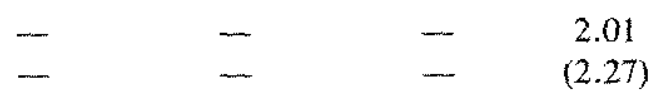

TAX

TAX -4
$\mathrm{R}^{2}$
$\mathrm{D}-\mathrm{W}$
$\mathrm{e}$

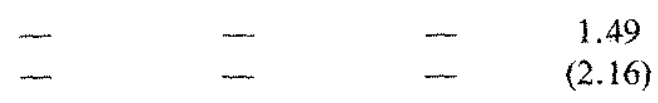

.9320

.9320

.9348

.9384

1.31

1.31

1.31

1.29

.912

.911

.902

.900 
equation. We thus base our discussion of these variables' effects on the results in column (4) of Table 2. Both the terms in the net replacement rate and those in the tax rate are significant, and the sum of each set of four coefficients is positive.

Since NRR grew from 095 in 1954:II to .265 in 1978:IV (reaching a high of .290 during the $1973-75$ recession), we may infer that the growth of transfer payments relative to net wages and salaries has induced an increase in the unemployment rate. A similar inference may be drawn from the positive coefficients on TAX and the increase in TAX from .167 to .301 (its highest value) during this period. However, lest this be reported in tomorrow's Wall Street Journal as proof positive of the deleterious effects of transfers and taxes on labor income, two considerations are in order. First, the coefficients imply incredibly large effects of taxes and transfers on the adjusted unemployment rate. For example, a one standard deviation increase in NRR from its mean is seen to induce an increase in $\mathrm{U}^{*}$ from its mean, 5.00, to 7.85. Similarly, an increase in TAX of one standard deviation from its mean of .231 induces an increase of $U^{*}$ from its mean to $6.08 .^{\circ}$ Both of these are ridiculously large, suggesting other things are going on that we have not accounted for. Second, it may be the skepticism of one who has seen too much simple-minded macroeconometric "evidence," but 1 tend to disbelieve studies whose bold conclusions are based solely on time-series results. Accordingly, I would give little weight to the results in this section, and would instead base my conclusions on careful thought about the programs' effects and on cross-section evidence about their impact.

\section{SOME THEORETICAL CONSIDERATIONS}

Given my skepticism about using macro estimates of the effects of taxes and transfers on unemployment to deduce their effects on the NAIRU, it is incumbent upon me to propose some alternative method of answering this question. Heip is provided by the approach of Perloff and Wachter (1979) and others who use aggregate production and pricing models to deduce what aggregate unemployment rate, adjusted for demographic change, is consistent with nonaccelerating inflation. This method is clearly the correct

'In an equation like that in column (4) from which TIME was excluded, the sum of the coefficients on NRR was 5.35, and that on TAX was 3.00 .

NRR bas a mean of .171 and a standatd deviation of .060; TAX has a mean of .231 and a standard deviation of .040 . Their correlation is .933 . 
one for macro policy planjing; it does not, though, as its users would readily admit, indicate whether changes in tax and transfer policy are responsible for changes in the NAIRU. (This approach really says little about the causes of changes in the NAIRU.) Thus, while it may be helpful for other purposes, it provides no evidence on the positive issues under consideration here.

A second approach is simply to make grandiose statements about how the NAIRU has increased tremendously, or, depending upon one's political views, how unemployment much above four percent is evidence of a recession. In the former camp we have statements from at least one ex-Chairman of the Council of Economic Advisors; sympathetic to the latter, a recent annual report of the Council of Economic Advisors made the bold admission that, "A number of forces have been at work... to raise the overall unemployment rate at which inflationary pressures begin to appear above the neighborhood of 4 percent... ? ${ }^{\top}$ Neither statement has the least bit of scientific basis, and neither should therefore receive any serious attention. Nonetheless, because of the political importance of the issue, and because of the attention those making such statements command, they have infected the public debate. They do not, though, tell us anything about how or to what extent transfers and taxes have affected the labor market.

A third approach is inductive; it tries to construct, from available estimates of the effects of individual tax and transfer programs, the likely impact on the NAIRU of the sum of such programs. The problem with this approach is that, unless one examines the underlying estimates carefully before basing one's conclusions upon them, one quickly comes to outlandish results. For example, taking Feldstein's (1973) estimate that unemployment insurance (UI) benefits and taxes induce a 1.25 percentage point increase in the NAIRU, and combining it with Clarkson and Meiners' (1977) estimate that AFDC and Food Stamps work registration requirements have raised measured unemployment by two percentage points, the absurdity of the exercise becomes apparent. It is impossible to believe that without these two fairly small programs, the unemployment rate in 1979 would have been reduced to below 3 percent. Either these effects are not additive, or the

\footnotetext{
"Herbet Stein noted, "I am not in a position to insist that it [full employment] is 7 percent unemployment. But it is a possibility that must be given weight. Suppose we accepted the idea that there is a $50-50$ chance that we are now at full employment." (Wall Street Journal, September 14, 1977, p. 22) The CEA statement is from the Report, 1978, p. 171.
} 
underlying estimates are grossly overstated. (The former criticism may be correct, though I present no evidence on it; the latter does, as I show below, have substantial support.) Given these difficulties, this third approach is also not one that is likely to produce precise estimates unless great care is given to the interpretation of the underlying studies.

What I do here is recognize that the NAIRU has increased since the 1950 s, probably by the slightly more than 2 percent implied for 1977 by the Perloff and Wachter study. Of this increase a bit more than one percentage point has been attributed by Wachter (1976) to changes in the demographic mix of the labor force. Using the four groups underlying the calculation of $U^{*}$ in the estimates in the previous section, I find that the unemployment rate would have been .85 percentage points lower in 1978:IV had the labor force weights of 1957:I prevailed. (I am somewhat uncomfortable with the assumption implicit in this approach that the relative unemployment rates of the various demographic groups must remain unchanged from 1957 . In any case, those who loved the implications of this approach for the 1970s' labor market may be less enthralled with its implications for the late 1980s!) The task, then, is to consider on a program-by-program basis whether the remaining one percentage point increase could have been produced by changes in transfer policy. In conjunction with this we consider whether the slowdown in the growth of real output per capita may also have been in part induced by these policy changes.

Although it is impossible to summarize in a succinct way the massive amount of theoretical work on the incentive effects of various transfer programs, I believe that there are sufficient general similarities among the programs' effects to make a general discussion of their likely economic impact worth while. The purpose of doing so is to point out some aspects of these effects that have been ignored by research that has been concentrated narrowly; to demonstrate the similarities among various strands of research; and to provide a focus for the discussion of specific programs' effects in the next section. Throughout this analysis we assume that leisure and unemployment are synonymous - both are voluntary. We also recognize that any attempt to synthesize a general model will surely ignore some important programmatic details within individual transfer schemes.

We examine the likely effects of transfers under the assumption that each member of the adult population faces two separate situations vis $\mathrm{a}-v i s$ these programs. In the first the individual is 
FIGURE 1

Budget Constraints Before Eligibility for Benefits

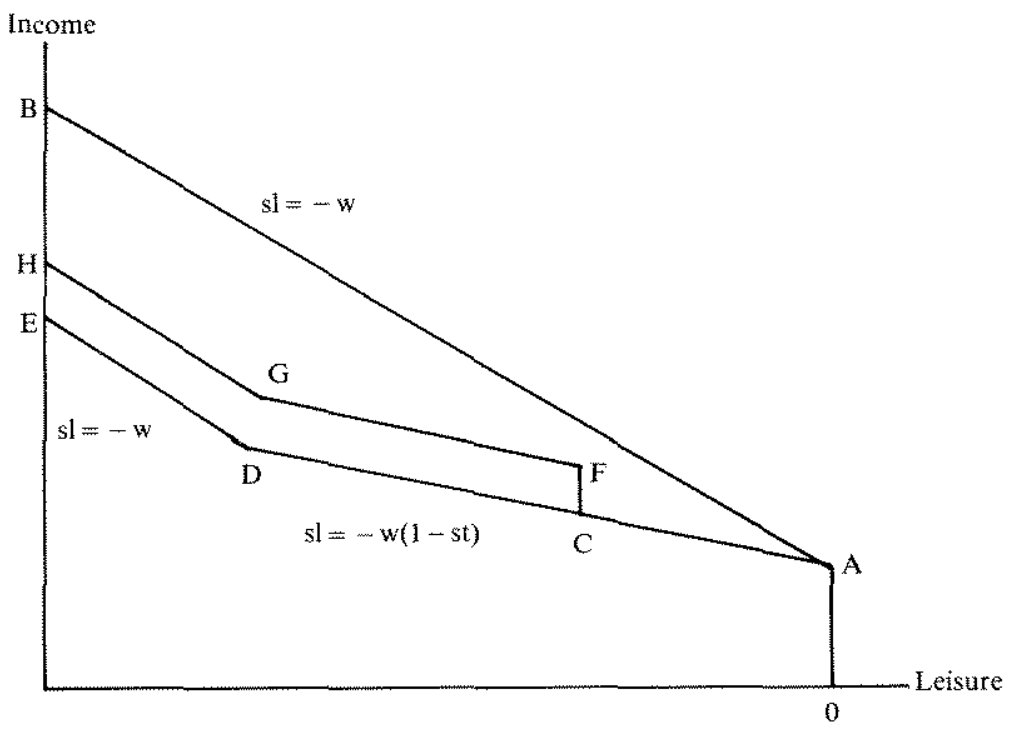

ineligible for benefits under the program. Nonetheless, the program affects his behavior because of the incentives it provides to establish eligibility for benefits later on. This represents the entitlement effect discussed for UI in Hamermesh (1979b), part of the effect of OASI on hours of work before age 62 implicit in Burkhauser and Turner (1978), and the work incentive effect of OASI through automatic benefit recomputation noted in Blinder et al. (1980). As Figure 1 shows, the budget line in the absence of the transfer scheme (and the taxes that finance it) is $O A B$. With the transfer program and its concomitant tax structure the line shifts to OACFGH. As compared to the budget line OADE, describing the choice set available to the worker who sees only the wage net of taxes, the constraint OACFGH induces substantial changes in behavior. (See Moffit and Kehrer, 1980; Burtless and Hausman, 1978; and Hamermesh, 1980.) Some persons who would have been at the corner solution at $\mathrm{A}$, or who would have found an internal maximum along $\mathrm{AC}$, are induced by the entitlement aspect of the transfer program to increase their supply of labor and move to point $F$. (In addition to its effects in UI and OASDI, it may also be operative in affecting military enlistments, as the post-service educational and other benefits are an added bonus to enlistees.) Though this entitlement effect has no immediate impact upon unemployment rates, it may 
FIGURE 2

Budget Constraints When Eligible for Benefits

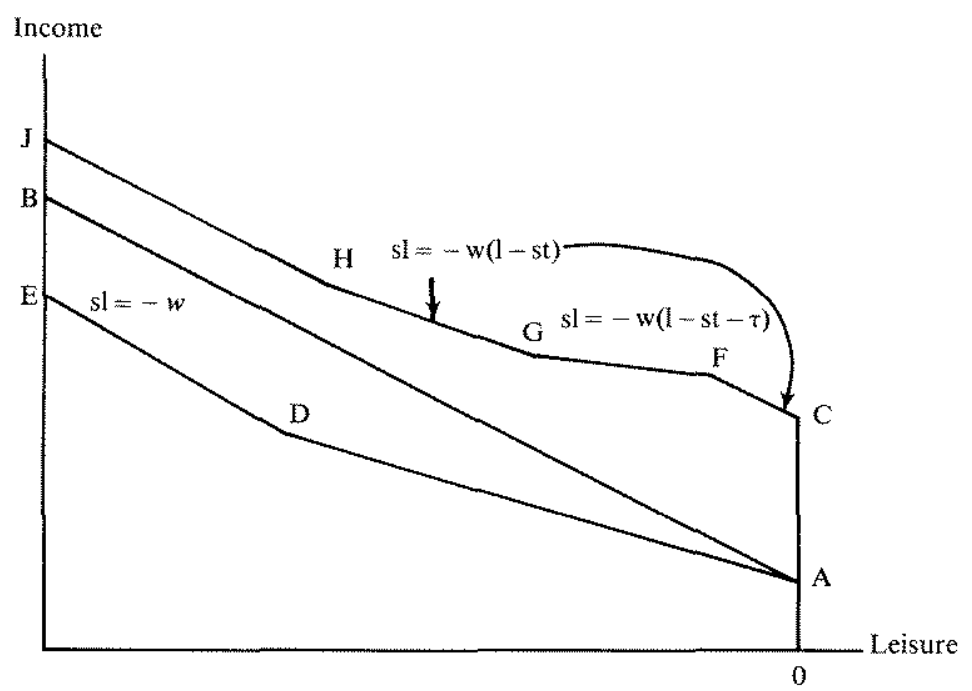

change the aggregate rate insofar as it increases labor force participation among persons whose probability of being unemployed differs from the average. So too, it will clearly increase market employment and thus measured real GNP.

Once eligibility for the transfer is established, the individual faces a different set of constraints. Under UI and OASDI these can mutatis mutandis be described as resulting from a lump sum benefit paid if no work, or only a small amount of work, is undertaken; as reflecting the sum of the wage rate and a steadily reduced benefit as hours increase, until the point at which no more benefits are paid. The budget line OACFGHJ in Figure 2 describes this choice set. As compared to the case in which the only perceived effect is through the tax (along OADE), the impact of the program is to induce those who otherwise would have supplied labor along FC to reduce their supply (assuming leisure is a normal good). This effect likely occurs beneath the ceiling on OASI benefits (currently $\$ 5000$ per year), though this does not appear to have been analyzed empirically; and the same effect is expected beneath the $\$ 280 /$ month at which an individual no longer is eligible for Disability Insurance.

In addition to the possible effect in shifting persons rightward from $\mathrm{F}$ in Figure 2, transfer programs also shift them from points to the left of $F$ toward point $F$. These are the disincentive effects that have received so much attention in the literature (see Feldstein, 
1973, and Hamermesh, 1977, on regular UI; Munts, 1970, on partial UI benefits; Quinn, 1977, and Boskin, 1977, on OASI; and Parsons, 1980, Leonard, 1979, and Haveman and Burkhauser, 1980, on DI.) In each program there is some, occasionally nearly infinite, tax rate on additional earnings beyond point $F$ such that labor supply is reduced. It is this effect that has been viewed as the culprit in reducing market employment and, in the case of leisure that is measured as unemployment, in increasing the unemployment rate.

Throughout the discussion we have glided over the effect of taxes that finance the transfer payments. Since the concentration of this paper (and most of the literature) has been on the effects of transfers, that seemed appropriate. Nonetheless, some attention to this difficult issue is in order at this point. The following considerations seem relevant. 1) At least for transfer programs, the issue of what the financing method does to labor supply is unusually murky because of the extreme difficulty of extricating the effects of taxes that are, for some programs, experience rated (see Hamermesh, 1977, and Ehrenberg et al, 1978). 2) Assuming that the financing is through a payroll tax, a very complicated simultaneity problem seems to be operating. Without knowing the incidence of the combined employer-employee tax that finances OASI and DI, we cannot know the true shape of the budget constraint facing the worker-consumer. But, without knowing the shape of the constraint, we cannot deduce the labor supply elasticity that partly determines the incidence of the tax. This means that any consumer-theoretic analysis of the effect of a combined tax-transfer program rests on shaky ground. 3) Despite these problems, we do know that the payroll taxes are at least partly borne by workers, so that it makes sense to represent the slope of the budget lines OADE in Figures 1 and 2 as $-w(l-s t)$, where $w$ is the wage rate, $t$ is the (total) tax rate, and $s$ is the fraction of the tax borne by workers. 4) Because of the ceiling on payroll taxes, there is a convexity in the budget constraint facing the workerconsumer over some range. This will affect labor supply and thus market output in that range. (Clearly, though, if one modeled the entire structure of taxes on earnings, one would find that the appropriate constraint is concave to the left of some point.)

The net effect of taxes and transfers on aggregate supply combines all of these separate impacts implied by this general model. Entitlement effects, induced unemployment, bunching at notches in benefit structures, and behavior induced by taxes, either 
general income taxes or earmarked taxes that finance a particular program, must be considered as we discuss how each specific transfer program affects the labor market.

While our discussion abstracts from changes in the demographic mix that have affected the NAIRU, we should recognize that there are other changes in the composition of the labor force that are induced by transfer schemes and that will have an impact on the NAIRU. Within each demographic group, for example, those persons with the lowest market productivity (relative to their productivity at home) will be induced to leave by any given increase in transfer payments. So long as relative market-household productivity is positively (negatively) correlated with the individual's probability of being employed when in the labor force, this will induce a decrease (increase) in the measured unemployment rate within the particular demographic group. Though this is a change induced by transfers, it is also a measurement problem of a sort similar in quality to that which we have circumvented by assuming constant labor-force weights.

\section{EFFECTS OF SPECIFIC TRANSFER ANd TAX PROgRams}

That transfer payments have formed an increasing fraction of disposable income was made clear in our discussion in the second section, and it is underscored by the totals in the bottom two lines of Table 3. The growth of transfer payments has been very uneven, however; it is interesting to note that the phrase "welfare mess" is hardly apropos, as "welfare"-usually thought of as AFDC-has grown more slowly than disposable income. Disability Insurance payments have been the most rapidly growing among programs that were ongoing in 1966, and we have seen the birth and explosive growth of payments under SSI and Food Stamps. The data clearly suggest that transfers could, by virtue of their increased generosity and coverage, have induced substantial changes in the labor market since the mid-1960s. Whether this is in fact the case can be seen by a program-by-program consideration of the transfers' effects.

Prompted by Feldstein's (1973) seminal work, there was a resurgence of research on the effects of UI on the labor market. Unfortunately the bulk of this work is on only one of the potential impacts of UI, namely on the duration of spells of unemployment. The twelve studies summarized in Hamermesh (1977, Chapter 3) show a substantial consensus that higher UI benefits do induce people to remain unemployed longer (as our discussion in the previous section suggested). Further work (e.g., Kiefer and 
TABLE 3

Income Maintenance Programs

1966 and 1978

(billions of dollars)

\begin{tabular}{|c|c|c|c|}
\hline Program & 1966 & 1978 & $\begin{array}{l}\text { Growth Rate } \\
\text { ( } \% \text { per year) }\end{array}$ \\
\hline $\begin{array}{l}\text { Old Age and Survivors' } \\
\text { Insurance }\end{array}$ & $\$ 18.071^{\mathrm{a}}$ & $\$ 78.524^{\mathrm{a}}$ & 12.2 \\
\hline $\begin{array}{l}\text { Unemployment Insurance } \\
\text { (state and raitroad) }\end{array}$ & 1.891 & 9.233 & 13.2 \\
\hline $\begin{array}{l}\text { Workers' Compensation } \\
\text { (state laws and federal } \\
\text { programs) }\end{array}$ & 1.320 & 6.760 & 13.6 \\
\hline General Assistance (AFDC) & 4.306 & 10.700 & 7.6 \\
\hline $\begin{array}{l}\text { Food Stamps (value of } \\
\text { federal contributions) }\end{array}$ & $.065^{\mathrm{a}}$ & $4.595^{\mathrm{a}}$ & - \\
\hline $\begin{array}{l}\text { Disability Insurance } \\
\text { (under OASDHI) }\end{array}$ & $1.721^{\mathrm{a}}$ & $12.214^{a}$ & 16.3 \\
\hline $\begin{array}{l}\text { Supplemental Security } \\
\text { Income }\end{array}$ & - & 6.551 & - \\
\hline All Transfer Programs & 44.7 & 224.1 & 13.4 \\
\hline Disposable Income & 510.4 & 1458.4 & 8.7 \\
\hline
\end{tabular}

a Fiscal year basis

Neumann, 1979, and Katz and Ochs, 1980) has done nothing to dispel this consensus, and even my synthesis "best-guess" impact.5 extra weeks of unemployment for each .1 increase in the net replacement rate-seems supported by more recent studies. ${ }^{*}$ There should be no doubt whatsoever that UI benefits in the U.S. do induce longer spells of unemployment.

Feldstein (1976) and Baily (1977) have shown how the partly experience-rated tax that finances UI can induce increases in

\footnotetext{
${ }^{8}$ The weak evidence avalable suggests that this effect is smater in looser labor markets (Hamermesh, 1977, Chapter 3).
} 
employment fluctuations and thus increases in the number of spells of unemployment. This is postulated to occur because the marginal tax cost to employers of another layoff is zero. Many employers" UI taxes already exceed the benefits paid to prior employees because of nonzero minima on state UI taxes, and some others" taxes are limited by maxima on state tax rates. (Elsewhere, Hamermesh, 1977, I have shown that roughly only $2 / 3$ of UI taxes are experience rated.) Recently, there has been some effort to quantify the impact of the tax structure on the labor market. Brechling (1981) has carefully parameterized state UI tax laws and shown that they appear to have a substantial effect in raising manufacturing layoff rates across states and over time. Halpin (1979) has presented similar evidence for seasonal fluctuations in employment in several industries. I find this evidence, and the theoretical structure underlying it, to be nearly as convincing as that on unemployment duration.

The provision of UI benefits represents a safety net under workers' participation in the labor market. As such, it induces the potential worker to choose to participate where she otherwise might not. This entitlement effect (Hamermesh, 1979b) is especially likely to be important among demographic groups whose attachment to the labor market is fairly loose. It will affect the composition of the labor force by increasing the weight accorded to such groups, and will raise (lower) the aggregate unemployment rate if these groups' unemployment is greater (less) than average. I have shown for adult women that this effect does appear important in increasing participation, and one might assume that it affects the behavior of teenagers and older workers too. Since these groups generally have higher-than-average unemployment, we may infer that it adds to the positive effect of UI on aggregate unemployment. However, by inducing persons marginally attached to the labor market to spend more time in the work force, it also increases market employment in these groups.

The net effects of an expanded UI program - higher benefit amounts, longer potential duration and wider coverage - have been clearly demonstrated empirically: Unemployment duration is raised; employment variability is increased, and the composition of the labor force is tilted toward groups having higher-than-average unemployment. There is no question that UI raises the NAIRU, by an amount that I elsewhere (Hamermesh, 1977) have "guesstimated" to be .7 percentage points. Part of this effect has been added since the mid-1960s, due to expansion of coverage of 
this program and to recession-triggered extensions of the potential duration of benefits. The program also induces declines in employment (as unemployment duration is increased, and additional layoffs occur when product demand decreases), but may also increase market employment among secondary workers. The net effect on aggregate employment, and thus per-capita GNP, is an empirical question; however, as I have shown elsewhere (Hamermesh, 1979b) that even among adult women the net effect is negative, we may conclude it is negative in aggregate as well.

As Table 3 shows, retirement benefits under Social Security represent the largest component of the transfer panoply. While our discussion in the previous section hinted at the program's major effects, there is one other effect that deserves mention first. Not only does OASI raise the cost of working for those eligible; the structure of benefits is also such that the cost is especially raised for younger eligibles. This occurs because: 1) at age 72 the earnings ceiling is removed, whereas it applies before then; 2) the increase in monthly benefits if a man (woman) postpones filing beyond age 65 (age 62) is far less than would be actuarially fair; ${ }^{\circ}$ and 3 ) the ceiling on earnings is a more important constraint among younger eligibles, because their market wage rates are greater. These last two considerations coalesce to induce those eligible for benefits to file as soon as eligibility for full benefits is achieved. The removal of the ceiling at age 72 likely comes too late to have much impact on persons who have been out of the labor force, and whose skills have deteriorated.

Far more important than the induced switches among eligibles, the system has provided increasing incentives for early retirement through expanded support levels. (In terms of an ultra-rational lifecycle model, though, the opposite is true: The ratio of expected benefits to OASI contributions has been falling since the 1940s. In stuch a model the income effect works toward greater lifetime labor supply. I doubt people are that rational, and the participation data for older males in Table 1 suggest they are not.) As Muntell (1977) showed, these rose sharply between the late 19605 and 1976 , both because of ad hoc statutory increases and the now-repealed double indexing of benefits. Even though the 1977 Amendments will prevent further increases in gross replacement, the projected rises in

\footnotetext{
${ }^{4}$ Each month beyond age 65 in which benefits are not claimed raises the monthly benefit eventually claimed by $1 / 4$ of one percent; each month before age 65 in which benefits are clamed reduces the monthly benefit by $5 / 9$ of one percent. (Department of Heattls, Education and Welfare, Social Security Handbook, 1978)
} 
payroll tax rates, and a continuation of current trends in taxes on earnings, indicate that net replacement may continue rising. This suggests that the incentive that benefits give for early retirement will continue to increase unless further amendments to the Social Security Act are passed.

The magnitude of the increases in net replacement is large enough to have had substantial impacts on the labor market. Quinn (1977) and Boskin (1977) provide some weak evidence for the empirical importance of these effects in cross-section data, and Pellechio (1979) has provided a very convincing demonstration that it is higher Social Security benefits particularly that are responsible for the earlier findings. However, Blinder and Gordon's (1980) estimates show only slight effects. One might infer that the data on labor-force participation rates for older men in Table 1 reflect the time-series analog of this cross-section evidence. This effect has served to decrease employment; it says nothing per se about effects on the NAIRU. Indeed, our arguments on composition in the previous section; the observation that the unemployment rate among older males decreased between 1957 and 1979; and the evidence that early retirement is more likely among less educated, lower skilled workers, precisely those for whom incidence of unemployment is greater, all imply that the increased generosity of OASI benefits may have reduced measured unemployment by inducing nonparticipation by older workers with the poorest labormarket prospects.

We showed in the previous section that an entitlement effect can also exist in OASI payments, as workers seek to establish greater monthly retirement benefits later on through work before age 62 . This effect is compounded by the incentive the system provides to shift hours of work away from periods of eligibility for OASI, when the implicit marginal tax rate on effort is 50 percent. Burkhauser and Turner (1978) use aggregate time series to "show" that inclusion of Social Security wealth explains much of the sudden halt in the decline in the workweek after World War II. I am skeptical about attributing so much of this important phenomenon to what appears to be so far-removed an incentive, and I refuse to be convinced by time-series evidence alone. Some cross-section evidence seems to be required. Even without this, though, we should note that this effect implies an increase in labor input and market output, and probably no effect on the NAIRU, as hours are increased among prime-age workers whose participation rates are already high. 
Because the shared payroll tax finances OASI benefits, one cannot assess the program's effects without knowing the burden of the tax. While some aggregate evidence implies the burden is entirely on workers (Brittain, 1971), other macro evidence (Vroman, 1974) and micro studies (Hamermesh, 1979a) imply that it is shared by workers and capitalists through higher product prices. It is likely that the tax reduces effort. (I believe that substitution effects outweigh income effects for some groups, and that they are roughly equal for others.) However, though this does imply a reduction in total labor inputs into production, it may also imply a reduced NAIRU, since the greatest labor supply elasticities are among groups with a high incidence of unemployment (compare Borjas and Heckman, 1978, and Cain and Watts, 1973).

All these considerations suggest that OASI retirement benefits change labor-force participation in such a way as to reduce the NAIRU: The composition of the labor force is induced to shift toward groups with a low incidence of unemployment. With the exception of the (to me) secondary effect on the distribution of hours of work over the lifetime, the theoretical arguments and empirical evidence suggest the major impact of OASI retirement benefits is to decrease employment. Because of increased net replacement and earlier eligibility, this effect has moreover likely increased since the 1950s, and has increased since the late 1960s for the first of these reasons.

Federal Disability Insurance has since 1960 provided benefits to disabled workers of all ages. As Table 3 showed, the program has received increasing attention from potential eligibles, drawn by increased replacement rates and a not overly harsh interpretation of eligibility rules. While there is a five-month waiting period during which the person is not to be involved in substantial gainful activity, an initial denial of benefits still leaves the applicant four appeals levels; and the evidence (Haveman and Burkhauser, 1980) suggests that claimants are increasingly aware of this and increasingly successful in their appeals.

Like OASI under Social Security, Disability Insurance provides incentives that affect the NAIRU and aggregate employment. Workers with low market productivity, either because of severe impairments or because of minor impairments coupled with a lack of marketable skills, have a substantial incentive to apply for and continue to seek DI benefits. (This is not, though, a decision to be made lightly: Once eligibility is established, the individual cannot earn more than $\$ 280$ per month and then reapply successfully for 
benefits.) We should thus expect low-wage workers, minority workers, older persons, etc., to be represented disproportionately among DI recipients. Indeed, one might view DI partly as a retirement program for those in their fifties.

These predicted effects are exactly what we observe: Leonard (1979) shows that among males $45-54$ nonwhites have twice the representation among DI recipients as they do in the labor force. He also shows that the probability of filing for DI is negatively related to one's past wage rate. ${ }^{10}$ Haveman and Burkhauser (1980) show that the "overwhelming majority of DI benefits are initially made [sic] to workers age 50-64."

The most clearly demonstrated impact of the program's increased legal and administrative attractiveness to potential eligibles is on the labor-force participation of older men. Among nonwhites, for example, Siskind (1975) has shown using time-series data that much of the decline in participation can be attributed to the changes in the DI program. In a more complex model Leonard (1979) confirms Siskind's results. Parsons (1980) finds similar results for the participation of males ages 48-62 using cross-section data for 1969. He also finds that the effect of higher DI benefits in 1969 is greater among persons who died within the next few years and who presumably were in poor health when they filed for benefits. The results suggest strongly that the growth of DI has induced a decline in the NAIRU. All the groups which the program data and empirical work demonstrate are induced to leave the labor force are composed disproportionately of persons with an above average incidence of unemployment. This means that the composition of the labor force is shifted by DI benefits away from persons with higher unemployment rates, and thus that measured unemployment is lower at a given level of labor market tightness.

The effects of DI on the labor-market issues of interest - the NAIRU and the size of the work force-are the same as those of OASI: Market employment is reduced, as is the NAIRU. This rapidly growing program may well have contributed to reducing the rate of GNP growth, but it has also disguised some of the unemployment that would otherwise have been observed.

While the Food Stamp program is relatively new and has grown rapidly, AFDC payments were established under the Social Security Act and have grown relatively slowly in the last decade.

\footnotetext{
"Because of the problem of specifying full-capacity eartings to hold constant for the effects of health on the probability of filing, Leonard's results should be viewed as quite tentative.
} 
Analytically, though, they can be lumped together for our purposes. The first consideration for each program is the work registration requirement each entails: Recipients of benefits must register with the state Employment Service and accept suitable work if such is found for them. Clarkson and Meiners (1977) have argued that this has induced a 2 percentage point increase in measured unemployment. The calculation is based on the assumption that no registrants would have been in the CPS labor force before the work registration requirement was imposed, and that all report themselves as unemployed in the CPS. Both assumptions seem highly questionable, and Cagan (1977) and Devens (1978) have argued that the Clarkson-Meiners number is greatly overstated. Without econometric evidence based on observation of the effect of Food Stamp or AFDC on labor force status, little credence appears owed to this finding. One would need longitudinal data to test the issue properly; though such are available, the test has not been undertaken. Perhaps the best conclusion on the issue, based upon consideration of the enforcement of the work-seeking requirements, is that there may have been some one-shot effect on the NAIRU in the early 1970 s, but it was likely tiny.

If one believes the registration effect on the NAIRU was important, one must also believe that the requirement has induced an increase in employment and thus in aggregate supply: Some of these induced to register presumably did find work when they otherwise would not have. Since I do not believe the effect on the NAIRU is large, I do not believe this positive effect on employment is large either. Far more important is likely to be the effect of the benefit structure under both programs. Saks (1975), for example, has shown that the implicit tax rate on AFDC mothers in New York in 1967 was .6, and that there was a substantial guarantee. (Casual evidence suggests the implicit tax rate is somewhat lower today.) Similarly, Food Stamps have increasingly substituted for the negative income tax that was never enacted: There is no longer a purchase requirement; a certain amount of Food Stamps is guaranteed, and the allotment is reduced by less than 100 percent as other income increases. This implies that both programs will induce the usual negative effects on labor supply that we know are associated with negative income taxes, assuming, as seems likely, that recipients' supply elasticities are positive (see Saks, 1975, for strong evidence on this).

How much have the induced changes in labor supply resulting from $A F D C$ and Food Stamps changed the NAIRU and aggregate employment in the past 15 years? Since AFDC has not expanded 
relatively, it is hard to argue its effect has changed, so that one must conclude it has not contributed to higher unemployment or a changed employment rate. (Though, clearly, reducing the guarantee or the tax rate would increase supply.) Food Stamps are new since the mid-1960s, though; it is thus likely that they have affected unemployment and employment. However, as with the other programs that have reduced labor supply, one can reasonably argue that the reduction has been disproportionately among persons with the highest incidence of unemployment. Thus, if anything, the benefit structure of Food Stamps has reduced the NAIRU slightly. Without careful econometric evidence (and there is currently none), this conclusion is based only on a little logic and on an analogy to the demonstrated effect of other programs whose benefits can be modelled similarly to those of Food Stamps.

There are numerous other transfer programs that one could examine, and some, such as Workers' Compensation or Supplemental Security Income, are fairly important. However, there has been little or no work studying the effects of these other programs on the NAIRU or on employment; since the discussion above has given the flavor of the likely directions of the impacts of most programs, there is little point repeating the analysis absent specific empirical results. Suffice it to say that these other programs most likely accentuate the effects we have already discussed.

I have avoided analyzing the effect of income taxes on the NAIRU and on aggregate supply. While the latter issue has received tremendous popular attention (and far too little scientific analysis), the former has received none. There is no obvious direct effect of the progressive income tax on the NAIRU, though there may be some compositional effect of the sort we have stressed throughout this section. Whatever the impact of the income tax on the labor supply of high-wage earners, it is unlikely to have induced them to withdraw from the labor force. A reduction in weekly hours seems far more likely. Thus if anyone is induced to reduce market work to zero, it is probably those whose market opportunities are least attractive. To the extent that the income tax does affect supplyand, I stress, this has not been demonstrated directly - it has likely done so among persons with the greatest probability of being unemployed. Thus, if anything, the progressive income tax reduces the NAIRU by changing the composition of the labor force.

The effect of the progressive income tax on hours of employment cannot be answered here. (Hausman's paper covers this in more detail.) Nonetheless, we should note that the induced reduction in 
output (assuming wage rates reflect marginal productivity) is $\sum_{i} \eta_{i} w_{i} N_{i}$, where $t$ is the marginal tax rate on the ith group of i

potential workers; $n$ is their labor supply elasticity; $w$ is their market wage, and $N$ is the number of persons in the group. Across different groups of workers both a higher marginal tax rate and a higher supply elasticity will induce a greater reduction in effort (and thus presumably in market output and real GNP). Among highwage groups the marginal income tax rate on effort is fairly high; however, all the available evidence suggests $\eta$ is quite low (Borjas and Heckman, 1978). Thus it is unlikely that income taxes are inducing much shortall of output from this group and, conversely, laughable to think that tax reductions will induce a sharp rise in workhours and total earnings.

For low wage groups the evidence is much less clear. While it is true that most studies find fairly high values of $n$ for these groups (see Cain and Watts, 1973), some tecent evidence suggests that, at least for women with children, these findings are due to fixed costs of entering the labor market (see Cogan, 1980). This suggests that the effect of increases in the marginal tax rate on hours of effort will be small. Also, the marginal tax rates on low-wage workers are not very high.

Taken together, the evidence says that it is unlikely that the progressive income tax has reduced employment much. Noreover, it has, if anything, reduced the NAIRU. There may be difficulties with the current income tax structure in this country; taxes may be "too high"; but these statements should not be based on fears about any huge detrimental effects on the labor market.

\section{CONCLUSIONS}

I would like to give one grand number indicating the effect of income transfer programs on the NAIRU. I cannot. All I can do is note that UI does raise unemployment, but that the other, often larger-scale programs have the opposite impact through their effects on the composition of the labor force. Since I have not been able to quantify these, I cannot weigh them against the effect of UI that I have previously "guesstimated." Nonetheless, if forced to pick one number to summarize the entire impact of transfers and taxes on the NAIRU, zero would appear to be a good choice. At the very least, it is a far better choice than that implied in the regressions in the second section or in much of the popular discussion. 
Zero would be a very bad estimate of the effect of taxes on aggregate employment, Every program we have discussed likely reduces labor supply on net. While we have not quantified this reduction for all the programs and taxes discussed, the studies that have done so for particular programs suggest the decline is substantial. That transfers induce such a reduction should be especially disturbing, as the tax structure in the U.S. economy already contains a (probably increasing) bias against market work. (Though, as we saw above, its effects may not be very large.) While guessing the size of the induced drop in employment is not possible, it is worth noting that, if even one-half of the decline in participation of men 55 + has been caused by changes in OASI and DI benefits and regulations, that alone would have induced a .8 percent reduction in aggregate employment since the mid-1950s. The effect for the entire labor force is likely somewhat larger than this. This guess, though, creates a conundrum: Why has aggregate labor force participation risen by 3.6 percentage points since 1969 , at the same time we estimate that taxes and transfers have induced a decline? Have nonmarket substitutes for women's time in the home experienced such huge relative price reductions? Has the structure of tastes changed (a thought that is repugnant to me as an economist)? Perhaps the real issue we should be addressing is: Why has the aggregate participation rate grown so much, departing from its long-term near constancy just below 60 percent?

While this is not a policy paper, a few conclusions for policy seem clear. The evidence is abundant that we cannot ease program eligibility and pay higher benefits without inducing changes in behavior. This raises program costs, and thus the taxes that finance the programs, and it targets benefits toward persons who were not (at least apparently) meant to be targeted. At a time when the older population is becoming healthier, DI bas induced substantial decreases in participation of men 55-62. OASI benefits have done the same for persons $62+$ and caught them in what Maggie Kuhn of the Gray Panthers has called the "retirement trap": They are induced to leave the labor force early, find they cannot maintain their financial status during an unexpectedly long retirement, and discover it is difficult to reenter the labor force at the same rate of earnings." Clearly, unless we wish to see the growth rate of real per-capita income decline further, steps such as raising the

\footnotetext{
"Case histories and a discussion of this problem are presented in Wall Street Journal, November 5, 1979, p. 1 et. seq.
} 
minimum age of eligibility back to 65 for men, and 62 for women, seem perfectly reasonable and consistent with a healthier and longer-lived population. Similarly, DI cannot be allowed to grow further into a retirement program, as that will reduce the benefits that the politics of the program will allow to be paid to the seriously disabled who do need them. In short, we risk hurting those persons for whom all these programs were designed by letting them expand far beyond their original purposes with no thought to the tax burdens they impose or their induced effects on production. 


\section{REFERENCES}

Baily, Martin. "On the Theory of Layoffs and Unemployment," Econometrica, 45 (July 1977), 1043-1063.

Blinder, Alan and Roger Gordon. "Market Wages, Reservation Wages and Retirement." NBER Working Paper No. 513, July 1980 .

and Donald Wise. "Reconsidering the Work Disincentive Effects of Social Security." National Tax Journal (December 1980).

Borjas, George and James Heckman, "Labor Supply Estimates for Public Policy Evaluation." Industrial Relations Research Association, Proceedings, 31 (1979), 320-331.

Boskin, Michael. "Social Security and Retirement Decisions." Economic Inquiry, 15 (Jan. 1977), 1-25.

Brechling, Frank. "Layoffs and Unemployment Insurance." In Sherwin Rosen, ed., Studies in Labor Markets, Chicago: University of Chicago Press, 1981.

Brittain, John. The Payroll Tax for Social Security. Washington: The Brookings Institution, 1971.

Burkhauser, Richard and John Turner. "A Time-Series Analysis on Social Security and Its Effect on the Market Work of Men at Younger Ages." Journal of Political Economy, 86 (Aug. 1978), $701-716$.

Burtless, Gary and Jerry Hausman. "The Effect of Taxation on Labor Supply; Evaluating the Gany Negative Income Tax Experiment." Journal of Political Economy, 86 (Dec. 1978), $1103-1130$.

Cagan, Phillip. "The Reduction of Inflation and the Magnitude of Unemployment." In W. Fellner, ed., Contemporary Economic Problems, Washington: American Enterprise Institute, 1977.

Cain, Glen and Harold Wats. Income Maintenance and Labor Supply. Chicago: Rand McNally, 1973.

Clarkson, Kenneth and Roger Meiners. "Government Statistics as a Guide to Economic Policy: Food Stamps and the Spurious Increase in Unemployment Rates." Policy Review, 1 (Summer 1977), $27-54$. 
Cogan, John. "Labor Supply with Costs of Labor Market Entry." In James Smith, ed., Female Labor Supply: Theory and Estimation, Princeton: Princeton University Press, 1980.

Devens, Richard. "Food Stamps and the Spurious Rise in the Unemployment Rate Reexamined." Policy Review, 3 (Winter 1978), 77-83.

Ehrenberg, Ronald, Robert Hutchens and Robert Smith. "The Distribution of Unemployment Insurance Benefits and Costs." U.S. Department of Labor ASPER Technical Analysis Paper, No. 58,1978 .

Feldstein, Martin. Lowering the Permanent Rate of Unemployment.

U.S. Congress, Joint Economic Committee, 1973.

."Temporary Layoffs in the Theory of Unemployment." Journal of Political Economy, 84 (October 1976), 937-958.

Grant, James and Daniel Hamermesh. "Labor Market Competition Among Youths, White Women and Others." Review of Economics and Statistics, 63 (August 1981).

Grubel, Herbert and Dennis Maki. "The Effect of Unemployment Benefits on U.S. Unemployment Rates." Weltwirtschaftiches Archiv, 112 (1976).

Halpin, Terrence. "The Effect of Unemployment Insurance on Seasonal Fluctuations in Employment." Industrial and Labor Relations Reyiew, 32 (April 1979), 353-362.

Hametmesh, Daniel S. "Entitlement Effects, Unemployment Insurance and Employment Decisions." Economic Inquiry, 17 (July 1979b) 317-332.

. Jobless Pay and the Economy. Baltimore: Johns Hopkins University Press, 1977.

" "New Estimates of the Incidence of the Payroll Tax." Southern Economic Joumal, 45 (April 1979a), 1208-1219. "Unemployment Insurance and Labor Supply." Intemational Economic Review, (October 1980), 517-527.

Haveman, Robert and Richard Burkhauser. "Economic Issues Regarding Public Policy Toward the Disabled." Unpublished Paper, University of Wisconsin, 1980. 
Katz, Arnold and Jack Ochs. "Implications of Potential Duration

Policies in Unemployment Duration." Unpublished Paper, University of Pittsburgh, 1980.

Kiefer, Nick and George Neumann. "An Empirical Job-Search Model, with a Test of the Constant Reservation-Wage Hypothesis." Journal of Political Economy, 87 (Feb. 1979), 89-108.

Leonard, Jonathan. "The Social Security Disability Program and Labor Force Participation." NBER Working Paper No. 392, August 1979.

Moffitt, Robert and Kenneth Kehrer. "The Effect of Tax and Transfer Programs on Labor Supply." Research in Labor Economics, 4 (1980).

Munnell, Alicia. The Future of Social Security. Washington: The Brookings Institution, 1977.

Munts, Raymund. "Partial Benefit Schedules in Unemployment Insurance: Their Effect on Work Incentive." Journal of Human Resources, 5 (Spring 1970), 160-176.

Parsons, Donald. "The Decline in Male Labor Force Participation." Jotrnal of Political Economy, 88 (Feb. 1980), 117-134.

Pellechio, Anthony. "Social Security Financing and Retirement Behavior." American Economic Rewiew, 69 (May 1979), 284-287.

Perloff, Jeffrey and Michael Wachter, "A ProductionNonaccelerating Inflation Approach to Potential Output: Is Measured Potential Output Too High?" In Karl Brunner and Allan Meltzer, eds., Three Aspects of Policy and Policymaking, Amsterdam: North Holland, 1979.

Quinn, Joseph. "Microeconomic Determinants of Early Retirement." Joumal of Human Resources, 12 (Summer 1977), 329-346.

Saks, Daniel. Public Assistance for Mothers in an Urban Labor Market. Princeton: Industrial Relations Section, 1975.

Siskind, Frederic. "Labor Force Participation of Men 25-54, by Race." Monthly Labor Review, 98 (July 1975) , 40-42. 
Vroman, Wayne. "Employer Payroll Taxes and Money Wage Behavior." Applied Economics, 6 (June 1974), 189-204.

Wachter, Michael. "The Demographic Impact on Unemployment." In National Commission for Manpower Policy, Demographic Trends and Full Employment, Special Report No. 12, 1976. 